\title{
Objective Consequentialism and Avoidable Imperfections
}

\author{
Rob van Someren Greve
}

Accepted: 20 March 2012 /Published online: 4 April 2012

(C) The Author(s) 2012. This article is published with open access at Springerlink.com

\begin{abstract}
There are two distinct views on how to formulate an objective consequentialist account of the deontic status of actions, actualism and possibilism. On an actualist account, what matters to the deontic status of actions is only the value of the outcome an action would have, if performed. By contrast, a possibilist account also takes into account the value of the outcomes that an action could have. These two views come apart in their deontic verdicts when an agent is imperfect in an avoidable way, viz., when agent brings about less good than she could. In this paper, I offer an argument against actualism that draws on the connection between moral obligation and practical reasons.
\end{abstract}

Keywords Objective consequentialism · Actualism · Possibilism · Practical reasons · Avoidable imperfections

\section{Introduction}

There are two distinct views on how to formulate an objective consequentialist account of the deontic status of actions, actualism and possibilism. ${ }^{1}$ On the actualist account, what matters to the deontic status of actions is only the value of the outcome an action would have, if performed. By contrast, possibilism takes into account the values of the outcomes an action could have, at least insofar as it is within an agent's control what the outcome of an action will be. These views come apart in their recommendations for action in cases of avoidable imperfections, e.g., situations where an agent fails to realize the best possible outcome, even though she could have acted otherwise than she does (or will do). After sketching the two views

\footnotetext{
${ }^{1}$ There are, of course, various other choices one has to make in order to arrive at a clearly circumscribed consequentialist view; I will take a comparative, maximizing and act-centered approach for granted here. It is worth noting, first, that whether avoidable imperfections matter morally is a question that also arises for nonconsequentialists; what follows is, though, concerned only with an attempt to resolve it within a consequentialist approach. Second, actualism and possibilism as usually understood do not exhaust logical space. Some participants in this debate have advocated intermediary positions, neither fully actualist nor fully possibilist (see, e.g., Bykvist 2002, drawing on Goldman 1978, also see Carlson 1999, and Vorobej 2000). My aim here is merely to argue against actualism; as I indicate below (see note 17), an intermediate position might be acceptable.
}

R. van Someren Greve $(\bowtie)$

Department of Philosophy, University of Amsterdam, Oude Turfmarkt 141-147, 1012 GC Amsterdam, The Netherlands

e-mail: r.w.j.vansomerengreve@uva.nl 
and the issue that divides them in sections 1 through 3 , I offer an argument against actualism that draws on the connection between moral obligation and practical reasons, in section 4 . In a nutshell, the idea is that given a few seemingly innocuous assumptions regarding how an objective consequentialist should think about the nature and weight of practical reasons, actualist verdicts about cases of avoidable imperfections come out as incorrect. Sections 5 and 6 defend the argument's main premises against two objections.

\section{The Actualist Account of Obligation}

On a standard account of maximizing act consequentialism, whether a particular action is morally right, wrong, or obligatory depends completely on the value of the outcome of that action, as compared with the outcomes of the alternatives to it. ${ }^{2}$ My concern in what follows is with moral obligatoriness only. This notion can be defined more precisely in this way:

(A) An agent $\mathrm{S}$ ought to perform an action $a$ if and only if the outcome that $a$ would have if $a$ were performed is better than the outcomes that any of the alternatives to $a$ would have, if they were performed

I will take 'ought' to express overall moral obligation. I assume that it is the outcome that an action actually has, will have, or would have had, that is relevant to its deontic status, not the outcome an agent expects, foresees, should have foreseen, or intends. That is to say, our concern is with objective, not subjective forms of consequentialism. We can understand the notion of an 'outcome' in a broad sense, so it can include, for instance, the fact that an action of some type is performed. I assume that for every action, performed or unperformed, there is some determinate set of states of affairs that constitutes the outcome an action will have, if performed (or would have had, were it performed). ${ }^{3}$

Following widely used terminology, we can call (A) 'the actualist account of obligation,' or 'the actualist account,' for short. On the face of it, the actualist account is a plausible way to understand moral obligation in consequentialist terms. There is, however, at least one feature of it that even those otherwise sympathetic to its main ingredients may find objectionable, namely, that on the actualist account, what an agent will do can affect what she ought to do, even in cases where the agent could act differently than she will in fact do.

\section{Avoidable Imperfections}

The easiest way to explain the issue is by means of an example. Here is one made famous by Frank Jackson and Robert Pargetter (1986: 235):

Professor Procrastinate receives an invitation to review a book. He is the best person to do the review, has the time, and so on. The best thing that can happen is that he says yes, and then writes the review when the book arrives. However, ... were Procrastinate to say yes,

\footnotetext{
${ }^{2}$ I take the set of possible deontic statuses an action can have to be exhausted by these categories. There is no class of supererogatory actions given these assumptions; this is a standard feature of consequentialism.

${ }^{3}$ Each element of the set of relevant states is counterfactually implied by the action; viz., for any state of affairs $s$, if $s$ is part of the outcome of $a$, then $(a \square \rightarrow s)$. If the set of states that constitutes an action's outcome is maximal, i.e., if the set constitutes a complete way for the world to be, then this assumption amounts to what is known as counterfactual determinism (cf. Bykvist 2002). For some discussion of the plausibility and relevance of the assumption of counterfactual determinism to consequentialism, see Vessel (2003, 2007).
} 
he would not in fact get around to writing the review. Not because of incapacity or outside interference or anything like that, but because he would keep on putting the task off. ... Thus, although the best that can happen is for Procrastinate to say yes and then write, and he can do exactly this, what would in fact happen were he to say yes is that he would not write the review. Moreover, ... this latter is the worst that can happen. It would lead to the book not being reviewed at all, or at least to a review being seriously delayed.

Should Procrastinate accept the invitation? The outcome that accepting will have is worse than the outcome that declining will have, given that, ex hypothesi, were Procrastinate to accept, he would not write the review on time. On the actualist account, Procrastinate must therefore decline. It is crucial to the example that we do not take his failure to turn in the review on time after accepting as something that is beyond Procrastinate's control: he could, in whatever sense of 'could' we think is the relevant one in this context, write the review on time, but, as a matter of fact, he will not do so. ${ }^{4}$ The structure of the case is depicted by Fig. 1 .

Jackson and Pargetter present this case as an argument in favor of the actualist account, and they are far from alone in taking an agent's future actions to be normatively relevant in this way. ${ }^{5}$ However, one may just as well take a case like Procrastinate's as bringing out what is wrong with the actualist account, since it makes obligation sensitive to an agent's entirely avoidable imperfections. It sanctions behavior that is unnecessarily sub-optimal, and thus seems to go against one of the basic intuitions behind maximizing consequentialism, viz., that we ought to do the best we can (cf. Feldman 1986).

\section{The Possibilist Account of Obligation}

Dissatisfaction with the 'imperfection-sensitive' actualist verdict on cases like that of Procrastinate gives rise to the need for a different consequentialist account of obligation, one that better captures the underlying intuition. A standard way of formulating the alternative view is as follows ${ }^{6}$ :

\footnotetext{
${ }^{4}$ If there is no sense to be made of the idea that an agent can act differently than she will in fact act, then the two views might be mere notational variants of each other. Although this is a serious worry, both sides to the debate assume that cases like that of Professor Procrastinate are coherent, and so I'll leave this worry aside. ${ }^{5}$ For closely related consequentialist proposals, see Goble (1993) and Sobel (1976); see also Driver (2008), Goldman (1976), Louise (2009), and Woodard (2009). The more general idea that what an agent will do is normatively relevant also finds expression and support in literature not directly addressing the actualismpossibilism debate. Michael Smith (2004: 17-42) for example argues that we should act in the way that our fully rational selves would want us to act. In discussing how this differs from taking our fully rational selves as an example we should emulate, he comes down on the side of taking into account how we, as we actually are will misbehave in certain circumstances (ibid, 18-20). On basis of findings in empirical social psychology, John Doris (1998) recommends what he calls a 'situationist' model of ethical deliberation, which has as a central component the idea that we should not even try to do what a fully virtuous person would do in our situation, but rather should pay attention to how our less-than-fully-virtuous selves will be moved to act in non-optimal ways because of morally irrelevant features of our situation. Finally, there is quite some similarity between the actualist view and a view on how to accommodate problems of dynamic inconsistency in rational choice theory. Various authors (most notably, Hammond 1976, 1988) argue that a rational agent who faces a sequential choice problem ought to anticipate her future choices, and rule out strategies that she knows will not be followed through, even if those strategies promise a better end result. This view is known as that of 'sophisticated,' as opposed to 'resolute,' choice (see McClennen 1990).

${ }^{6}$ My characterization of possibilism closely follows that of Goble (1993: 136), Vessel (2009: 184), Vorobej (2000: 131), and Zimmerman (1996: 189-190). The possibilist account of Feldman (1986) differs in significant ways, as it characterizes moral obligation in terms of what states of affairs an agent sees to occurring in the best possible worlds (or 'life histories') that are still accessible to the agent at a time. It thus makes no use of the notions of acts, alternatives, or outcomes.
} 
Fig. 1 Structure of standard cases of avoidable imperfections

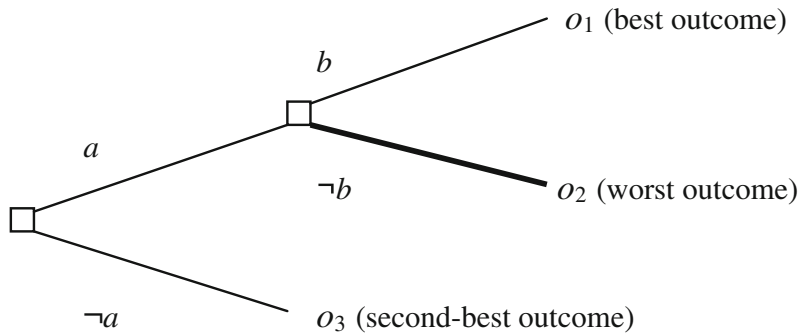

$t_{1}$ $t_{2}$

(P) An agent $\mathrm{S}$ ought to perform an action $a$ if and only if the best outcome that $a$ could have if $a$ is performed is better than the outcomes that any of the alternatives to $a$ could have, if they were performed

Call (P) 'the possibilist account of obligation,' or 'the possibilist account,' for short. If unqualified, the standard formulation of the possibilist account can be misleading, but I take it to be adequate as long as we understand 'could' as ranging only over those possible outcomes that it is within the agent's control to bring about. That is to say, while the set of relevant possible outcomes is restricted by what is metaphysically possible, it is further restricted by the agent's abilities. Put differently, it is the value of what an agent can see to, not what she will see to, that determines the deontic status of alternatives. ${ }^{7}$

On the possibilist account, it is not sufficient to attend only to the outcome that an action will have. In fact, it is irrelevant what outcome an action will actually have, if the actual outcome is not its best possible outcome, and the agent is able to bring about the best outcome. ${ }^{8}$ The case of Procrastinate illustrates the point: on the possibilist account, Procrastinate ought to accept the invitation, since the best outcome that accepting can have, is the best possible state of affairs that Procrastinate is able to bring about. The fact that he will in fact not write the review after accepting is irrelevant, given that he could do so.

Although the possibilist account sometimes rejects the normative significance of an action's actual outcome, we should treat it as a form of objective consequentialism. It counts as a form of objective consequentialism because it does not take deontic status to be dependent on what is foreseen, foreseeable, intended, or expected; like the actualist account, it rejects altogether the independent significance of the agent's epistemic or doxastic situation. ${ }^{9}$ Actualism and possibilism part ways over avoidable imperfections, that is, when an agent can bring about some other state of affairs than the one she actually brings about

\footnotetext{
${ }^{7}$ Restricting the set of relevant possible outcomes in this way should go some way towards answering the worry that an agent ought to perform actions where there is a great objective risk of a bad outcome, and what outcome will obtain upon action is dependent on a chance event that the agent has no control over. It may not, however, be sufficient to deal with cases in which agents have imperfect information, so that there is a high subjective risk associated with certain actions. As both actualism and possibilism are forms of objective consequentialism, both views may clash with intuitions supporting subjective consequentialism. For discussion, see Goble (1996), and Zimmerman (2006), among others.

${ }^{8}$ Put differently, the truth of the set of counterfactual conditionals that are a main ingredient of the actualist account is not always normatively relevant on the possibilist account as I sketch it here. It can be the case that, for some state of affairs $s, s$ is part of the outcome of $a$ (because the relevant counterfactual is true) yet the value of $s$ is nonetheless irrelevant to the deontic status of $a$.

${ }^{9}$ While on neither of these two accounts facts about the agent's doxastic or epistemic states directly affects the deontic status of an action, such facts of course can be relevant to the value of the outcome of an action, and in this way be indirectly relevant to what an agent ought or ought not to do.
} 
through her actions, not when an agent is less than fully informed about the relevant features of the situation.

In the remainder of this paper, I present an argument which, if successful, shows that actualism cannot be reconciled with the view on the weight of practical reasons that accords best with the basic tenets of a consequentialist approach to morality. After laying out the argument in the next section, the two sections that follow defend the argument's main premises against some objections.

\section{Against the Actualist Account}

Shifting focus from direct concern with the deontic status of particular actions to a focus on the practical reasons agents have for performing those actions is a move that has proven to be capable of furthering the debate in several other areas of normative theorizing. ${ }^{10} \mathrm{My}$ concern in what follows is with normative (or justifying) reasons, not with motivating (or explanatory) reasons. I assume that normative reasons to act are, or are provided by, the facts of an agent's situation, and more specifically, that they are, or are provided by, those facts or truths that count in favor of (or against) a course of action.

I'll argue that, given four claims about practical reasons that are independently plausible given a background commitment to maximizing consequentialism, the actualist account of obligation turns out to be untenable. The first claim concerns the relation between obligations and reasons:

Obligations Entail Reasons: If S ought to do $a$, then $\mathrm{S}$ has most reason to do $a$

Again, I take 'ought' to express overall moral obligation. Obligations Entail Reasons may need qualification, if (i) there are distinct types of practical reasons (moral, prudential, etc.), and (ii) moral reasons do not always outweigh other reasons. Even if that is the case, it is at least true that $\mathrm{S}$ has most moral reason to do $a$ when $\mathrm{S}$ ought to do $a$. I'll ignore this complication here; the qualifier 'moral' can be prefixed to every occurrence of 'reason' in what follows, if only the more restricted claim is true. ${ }^{11}$

Second, actions are, we might say, not the conceptually basic elements in a consequentialist normative theory; rather, it is states of affairs, or, more broadly, ways that the world might (or will) be, that are normatively fundamental. That is to say, for a consequentialist, all normative claims ultimately reduce to the (comparative) value of states of affairs. In light of this point, those sympathetic to a consequentialist account of deontic status, irrespective of whether they are actualists or possibilists, can be assumed to be sympathetic to what we can dub 'consequentialism about reasons' ${ }^{12}$ :

\footnotetext{
${ }^{10}$ See, e.g., the recent defenses of the "“ought' implies 'can"'-maxim by Vranas (2007) and Streumer (2007), both of which rely on the connection between obligations and reasons. Their linking premises are, though, significantly weaker than Obligations Entail Reasons.

${ }^{11}$ Obligations Entail Reasons would need further qualification if there are supererogatory actions, since it seems plausible that such actions would be actions an agent has most reason to perform, but they are not obligatory. As noted above (see note 2), there are no supererogatory actions on standard maximizing consequentialist accounts of deontic status, and so this point can be safely ignored.

12 Provided, that is, they hold that the relation between the deontic status of actions and the values of outcomes is direct; those attracted to indirect forms of consequentialism (such as rule- or motiveconsequentialism) will presumably not be willing to take this premise for granted. Those who reject consequentialism in any form will obviously not find this premise compelling either, of course.
} 
Consequentialism About Reasons: Practical reasons, i.e., reasons for action, are reasons to bring about particular states of affairs

Third, given a background commitment to consequentialism, it is overwhelmingly plausible to take the force of our reasons to bring about particular states of affairs to be a function of the value of those states. Of course, we cannot simply look at the value of any old set of different possible states of affairs in order to determine what a particular agent has reason to do or bring about. The range of relevant states is, it seems, at least restricted by what that particular agent is able to bring about through her actions. In other words, we should accept that (practical) reasons entail ability ${ }^{13}$ :

Reasons Entail Ability: If an agent $\mathrm{S}$ has a reason to bring about a certain state of affairs, then $\mathrm{S}$ is able to bring about that state

Reasons Entail Ability is compatible with both the actualist and the possibilist account. What it does is merely rule out from consideration states that an agent cannot bring about; however desirable some such states might be, they cannot provide agents with reasons if these agents are unable to make these states obtain. With this restriction on relevant states of affairs in place, let us next consider the force or weight of the reasons provided by the states of affairs she is able to bring about. What I take to be a natural, and intuitively compelling suggestion at this point is that the force or weight of the reasons an agent has is determined solely by the value of the states of affairs that she is able to bring about. That is:

Value Determines Weight: The weight of the reasons $\mathrm{S}$ has is determined by the values of the states of affairs that $\mathrm{S}$ is able bring about

The idea here is that we do not seem to need any more elements in order to say something substantive about where the balance of reasons is to be found in particular situations than the three previous claims; Value Determines Weight expresses this idea. Given a background commitment to maximization, Value Determines Weight is naturally taken to imply that an agent $\mathrm{S}$ always has most reason to bring about the best state that $\mathrm{S}$ is able to bring about.

Taken together, these four claims appear to provide a compelling reason to reject the claim that an agent $\mathrm{S}$ ought to do $\neg a$, a claim that actualism endorses, in cases with the structure depicted by Fig. 1. Informally, the argument goes as follows. Since S's doing $a \& b$ just amounts to bringing about the best outcome, whereas S's doing $\neg a$ amounts to bringing about the second-best outcome, S's reasons to do $a \& b$ must outweigh her reasons to do $\neg a$. This follows from Value Determines Weight. ${ }^{14}$ Given Obligations Entail Reasons, the fact that $\mathrm{S}$ 's reasons to do $a \& b$ outweigh her reasons to do $\neg a$ entails that it is not the case that $\mathrm{S}$ ought to do $\neg a$, since if it were the case that $\mathrm{S}$ ought to do $\neg a$, then $\mathrm{S}$ would have had most reason to do $\neg a$, and we have already seen that this is not the case. This conclusion straightforwardly contradicts the actualist claim that $\mathrm{S}$ ought to do $\neg a$. The argument can be summarized as follows:

P1. S has most reason to bring about the best state of affairs $\mathrm{S}$ is able to bring about $\mathrm{P} 2$. Doing $\neg a$ does not amount to bringing about the best state of affairs $\mathrm{S}$ is able to bring about

\footnotetext{
${ }^{13}$ For lengthy (and to my mind, compelling) defenses of the claim that practical reasons entail ability, see Vranas (2007) and Streumer (2007).

${ }^{14}$ This, of course, is not to say that $\mathrm{S}$ has no reason whatsoever to do $\neg a$; given that $\mathrm{S}$ can do worse, we can plausibly say that she has some reason to do $\neg a$. While that is true, it is beside the point.
} 
C1. Therefore, it is not the case that $\mathrm{S}$ has most reason to do $\neg a$

$\mathrm{P} 3$. If $\mathrm{S}$ ought to do $\neg a$, then $\mathrm{S}$ has most reason to $\neg a$

C2. Therefore, it is not the case that $\mathrm{S}$ ought to do $\neg a$

If successful, the argument shows that the actualist verdict on the relevant sort of cases, where agents are imperfect in avoidable ways, has to be rejected, because it is incompatible with an intuitively attractive account of what the balance of reasons supports in such cases.

\section{Rejecting P2}

How successful is this argument against actualism? If we set aside worries one may have about the connection between moral obligation and practical reasons sketched above and thus take P3 for granted, a proponent of actualism will have to reject either P1 or P2 (or both) in order to block the conclusion. I will discuss why one would want to reject either of these premises in reverse order, starting with $\mathrm{P} 2$.

Assume, for the moment, that it is agreed that what agents have most reason to do is determined by the value of the states of affairs those agents are able to bring about. It may be objected that this supports the claim that $\mathrm{S}$ does not have most reason to do $\neg a$ (as P2 claims) only if we interpret Value Determines Weight in such a way that it asserts that all of the states of affairs that $\mathrm{S}$ is, as of time $t$, able to bring about at some time or other, by way of one or more actions, count as states that $\mathrm{S}$ is able to bring about at $t$. Thus understood, the claim implies that there is a better state $\mathrm{S}$ is able to bring about as of $t_{1}$ (viz., $o_{1}$ ), but it is not a claim that is acceptable to the actualist. The actualist is willing to accept only that what $\mathrm{S}$ has most reason to do at $t$ is determined by the value of the states of affairs that $\mathrm{S}$ is able to bring about by way of actions $\mathrm{S}$ can perform at $t .{ }^{15}$ The set of relevant states of affairs, the value of which determines the weight of the reasons $\mathrm{S}$ has at a given time, contains only those states that are, as we might put it, available to $\mathrm{S}$ as of that time. The state of affairs brought about by doing $\neg a, o_{3}$, only comes out as insufficiently good in comparison to state $o_{1}$, but since bringing about $o_{1}$ requires the performance of $b$, and $b$ is not an action $\mathrm{S}$ can perform as of $t_{1}, o_{1}$ is not available to $\mathrm{S}$, and thus not included in the set of relevant states determining what reasons $\mathrm{S}$ has. Once $o_{3}$ is excluded from consideration, P2 loses whatever plausibility it may have had.

A first thing to note in reply is that if the criterion for denying that $\mathrm{S}$ is able to bring about $o_{1}$ at $t_{1}$ is that doing so requires the performance of an action that is not an alternative for $\mathrm{S}$ at $t_{1}$, then applying this criterion consistently rules out $o_{2}$ as a state that $\mathrm{S}$ can bring about at $t_{1}$ as well. If this is the line that the actualist wants to take, then it seems undeniable that the fact that $\mathrm{S}$ will not do $b$ at $t_{2}$ is neither here nor there; the fact that $o_{3}$ is a better state than $o_{2}$ is of

\footnotetext{
${ }^{15}$ A different way to put this point is this. The actualist may insist that she agrees that, if we take the set of relevant alternative actions to be $\{a \& b, a \& \neg b, \neg a\}$, then $\mathrm{S}$ indeed has most reason to perform $a \& b$, since she agrees that $\mathrm{S}$ ought to perform $a \& b$ out of this set of alternatives. However, when we ask, out of the restricted set of alternatives, $\{a, \neg a\}$, what action $\mathrm{S}$ has most reason to perform, we cannot appeal to the value of the state of affairs that $\mathrm{S}$ would bring about by doing $a \& b$, as that compound action is not an alternative open $\mathrm{S}$ at $t$. Since we are investigating what $\mathrm{S}$ ought to do at $t$, it is the restricted set that is relevant. And out of the restricted set, $\mathrm{S}$ has most reason, and ought to perform, $\neg a$. Formulating the point this way illustrates why actualism entails the rejection of the principle that 'ought' distributes over conjunction: it is both true, according to actualism, that $\mathrm{S}$ ought to perform $a \& b$ and that $\mathrm{S}$ ought to perform $\neg a$. See Goble (1993: 141-42), Jackson and Pargetter (1986: 247-49), and Sobel (1976: 204) for actualist rejections of the principle of distribution.
} 
no significance on this picture. In order to find out what $\mathrm{S}$ has most reason to do at $t_{1}$, it appears we need to introduce a further state of affairs, call it ' $o_{4}$ ', an intermediate state which consists of the choice node that $\mathrm{S}$ faces at $t_{2}$ if $\mathrm{S}$ would choose to do $a$ at $t_{1}$. The relevant comparison is now between the values of $o_{3}$ and $o_{4}$ : which of these states is better?

It is difficult at this point to resist the temptation to think that the value of state $o_{4}$, the intermediate state representing the second choice node, is dependent either on what state $\mathrm{S}$ could go on or on what state $\mathrm{S}$ will go on to bring about from that point. Indeed, it seems that unless we accept one or the other, we get results that are unacceptable irrespective of who has the upper hand in the dispute over actualism and possibilism. The basic problem is that it seems clearly permitted, and often morally required, to realize a comparatively worse intermediate state of affairs provided doing so is a prerequisite for realizing a superior end state, ${ }^{16}$ as when a doctor needs to first break a patient's crooked bones in order to surgically set them straight. If the doctor will in fact set them straight after breaking them, both actualism and possibilism hold that breaking the bones is morally required, but doing so is deemed impermissible on this criterion, provided the state in which the patient's bones are broken is worse than that in which they are not. But that is surely an unacceptable result. A satisfactory account of deontic status must be able to accommodate the permissibility of prerequisite actions.

Assuming that this result needs to be avoided, it seems that we either (i) will have to account for the value of the intermediate state $o_{4}$ by reference to what states the agent could or will realize from there onwards, or (ii) we have to ignore the intermediate state $o_{4}$ and focus only on the end states ( $o_{1}$ and $o_{2}$ ), as we have been doing so far. If we opt for (ii), we also face the choice between according weight to what the agent will do at $t_{2}$ and rejecting the significance of such facts. In the absence of independent considerations we can bring to bear on the matter, adopting either position on the significance of what $\mathrm{S}$ will in fact do at $t_{2}$ would render an argument that builds on this position question-begging, either against actualism or against possibilism (depending on which position we take). It may seem that we have reached a stalemate at this point. However, I believe this is not the case: there is at least one ground for doubting the actualist take on the value of $o_{4}$ (which makes the value of this state dependent on what $\mathrm{S}$ will do at $t_{2}$ ), or alternatively, the actualist insistence that $o_{2}$ is the relevant end state, a ground provided by the other claims offered in the previous section (which are not in question at this point).

Say that we accept the proposed restriction on which states of affairs count as those that an agent is able to bring about, so we take only the value of those states an agent can bring about by way of actions open to her at a given time as relevant to where the balance of reasons for her lies, as of that time. Up to this point, we have only looked at diachronic cases of avoidable imperfections, that is, situations where bringing about the best (and the worst) possible state of affairs involves the performance of several actions that are performable only at different times. Yet if what an agent will in fact do can matter to what she ought to do in diachronic cases, as actualism claims, we can reasonably expect this to show up as well in synchronic cases, that is, situations where distinct actions are jointly performable in different combinations at a single time. In such cases, though, the actualist verdict is incompatible with our assumptions, even if we understand Value Determines Weight in the restrictive way just suggested. To see that this is so, consider the following example, due to Holly S. Goldman (1978: 186):

\footnotetext{
${ }^{16}$ The need to accommodate obligations to perform prerequisite actions that do not by themselves realize anything good within consequentialist accounts of obligation has been recognized since Castañeda (1968). For discussion, see Feldman (1986: chapter 1).
} 
Jones is driving through a tunnel behind a slow-moving truck. It is illegal to change lanes in the tunnel, and Jones's doing so would disrupt the traffic. Nevertheless, she is going to change lanes-perhaps she doesn't realize it is illegal, or perhaps she is simply in a hurry. If she changes lanes without accelerating, traffic will be disrupted more severely than if she accelerates. If she accelerates without changing lanes, her car will collide with the back of a truck.

In this case, the states that the agent can bring about through her actions, \{Jones does not change lanes and does not speed up, Jones changes lanes and speeds up, Jones changes lanes and does not speed up, Jones speeds up and does not change lanes\}, which are ordered from best to worst, are all states that the agent can bring about at a single time. If what an agent has most reason to do at time $t$ is determined by the value of the states of affairs that she can bring about, and we restrict the set of relevant states to those that the agent can bring about by way of performing actions that are open to her as of time $t$, then Jones does not have most reason to accelerate right now, for by hypothesis, she would thereby not bring about the best state that she is able to bring about at this time. And this is so irrespective of whether she is going to change lanes: there is a better state that she can bring about by way of actions open to her right now, namely, the state in which she does not change lanes and does not speed up. Given Value Determines Weight (understood restrictively) and Consequentialism About Reasons, it follows that this is the state that she has most reason to bring about. And so what Jones will do is irrelevant to what she has most reason to do, contrary to what the actualist account predicts.

If what state of affairs an agent has most reason to bring about in synchronic cases of avoidable imperfections is not dependent on what she will in fact do, then theoretical simplicity surely speaks in favor of the (possibilist) view that what state of affairs an agent has most reason to bring about in diachronic cases is also not dependent on what she will in fact do. Other things equal, it seems reasonable to hold that either such facts always matter, or they never matter; if such facts do not matter in synchronic cases, then they also do not matter in diachronic cases. ${ }^{17}$ And, I submit, such facts do not matter in synchronic cases, as the example of Jones makes clear. The conjunction of Consequentialism About Reasons and Value Determines Weight explains why these facts do not matter in synchronic cases. If it is successful here, then presumably, this explanation carries over to diachronic cases.

In sum, restricting the scope of Value Determines Weight so that only states of affairs that can be realized by way of actions performable at a single, given time are included in the set of states the value of which determines what an agent has most reason to do neither supports the actualist view, nor does it lead to a stalemate. We need some way of dealing with the permissibility of prerequisite actions, and there is ground for rejecting the actualist treatment, so long as the other claims put forward in section 4 are uncontested.

\section{Rejecting P1}

In light of the foregoing, the actualist may want to change course at this point, and instead reject $\mathrm{P} 1$. Perhaps it is correct that $o_{3}$ is not the best state of affairs $\mathrm{S}$ is able to bring about (as

\footnotetext{
${ }^{17}$ I am not claiming that nothing could be offered in support of treating the two types of cases asymmetrically, merely that we are owed some non-question begging explanation of why we should treat them differently, if that is what the actualist would propose at this point. Note, though, that even if we were to treat the two types of cases asymmetrically, we still have to conclude that what an agent will in fact do is not always relevant; that would be enough to reject actualism (but insufficient for accepting the possibilist alternative-instead, this may lead us to accept some intermediate position; see note 1 for references).
} 
P2 entails), but why should she accept that this settles where the balance of reasons for S can be found as of $t_{1}$ ? If P1, and thus Value Determines Weight, does not state (part of) the intuitively most compelling way for a consequentialist to approach the question of what reasons agents have, $\mathrm{P} 2$ can be true without this posing a problem for actualism. Recall Value Determines Weight:

Value Determines Weight: The weight of the reasons $\mathrm{S}$ has is determined by the values of the states of affairs that $\mathrm{S}$ is able bring about

The actualist may object that this claim stacks the deck against actualism, since it takes an agent's reasons to be determined only by the value of what states it is possible for that agent to bring about, but this is something actualism denies. The actualist can propose an alternative account of how the value of states of affairs determines the balance of reasons, such as (say) the following:

Outcome Determines Weight: The weight of the reasons $\mathrm{S}$ has is determined by the comparative value of the outcomes of the actions $\mathrm{S}$ can perform

And, the suggestion could be, unlike Value Determines Weight, Outcome Determines Weight is neutral between actualism and possibilism, for we can spell out what the outcome of an action is either in actualist or possibilist terms: that is, we can either take an outcome of an action to be what will be the case if an action were performed, or we can take it to be (or include) what could be the case if it were performed. And with Outcome Determines Weight in place, the dispute between actualism and possibilism concerns the question of how we are interpret the notion of 'outcome'; the question of how our reasons (and their weights) are generated turns out to have no bearing on the matter.

By way of response, I want to suggest that Outcome Determines Weight introduces complications to the account of the weight of our reasons that are, if not in tension with the spirit of consequentialism, at least not supported by the basic consequentialist intuition. The basic, guiding thought which underlies consequentialist approaches to morality is that what matters ultimately is only how good the world is, overall. As Bernard Williams put it, for a consequentialist, ' $[\mathrm{w}]$ hat matters is what states of affairs the world contains, and so what matters with respect to a given action is what comes about if it is done, and what comes about if it is not done' (1973: 95). ${ }^{18}$ There are infinitely many ways the state of the world could be better than it is (or better than it will become), but obviously, not every possible improvement to the world is one that we are able to realize, be it individually or collectively. If, as I have been suggesting, our reasons (and their respective weights) are generated by the ways in which the world can be improved, then restricting the set of states of affairs that are relevant to what reasons we have to those states it is within our power to realize should be an uncontroversial move.

Any further way of circumscribing our reasons (and their weights) beyond the limits set by our ability to make the world one way rather than another, though, seems unmotivated, at least if we are guided by the basic consequentialist intuition. It is agreed on both sides that an agent's inability to realize a good state of affairs entails that this state is not one that the agent in question has reason to bring about (as Reasons Entail Ability makes explicit), but it is at best unclear why we need anything beyond these few ideas to arrive at a view about what

\footnotetext{
${ }^{18}$ Williams of course thought that this is (part of) what is wrong with consequentialism. Whatever one thinks of the criticisms Williams leveled against consequentialist accounts of morality, he was surely right in identifying this thought as a fundamental element of such accounts.
} 
reasons we have, and what their weights are. Tying our reasons for and against realizing particular states of affairs to whether or not these states are (part of) the outcome of an action, then, introduces more to our account than is needed to capture the basic consequentialist intuition, and thus doing so requires some motivation. But if I am right in claiming that the basic consequentialist idea is already fully captured by the set of claims put forward in section 4, considerations that can be offered in support of expanding the account of practical reasons will not be able to draw upon the basic idea, and thus appears to be unmotivated from a consequentialist perspective.

The suggestion is not that there cannot be a coherent account of where the balance of reasons lies in the sort of cases over which actualism and possibilism disagree that might turn out to sit well with the actualist view. I am trying to make a much more modest point: if we start from a few observations about what determines where the balance of reasons lies, observations that seem highly compelling from a consequentialist perspective, and we have not already taken a position about the dispute at hand, then there appears to be little (if anything) that speaks in favor of adding more to the picture than what figures in Value Determines Weight. When we ask the question how the value of different ways that the world can be generate reasons for agents while holding fixed the commitment to the fundamental consequentialist intuition that what matters ultimately is how well things are overall, what is there to recommend Outcome Determines Weight, when Value Determines Weight captures the basic consequentialist intuition in a straightforward and compelling way without having to introduce notions such as 'action' and 'outcome'? ${ }^{19}$ The step from 'what matters is how good things are overall' to 'what matters is how good I can make the world' is small, almost negligibly small; the same, however, cannot be said about the step to 'what matters is how good the world will turn out to be, if I act in such-and-such way.' Our reasons to act just are reasons to bring about states of affairs (as Consequentialism About Reasons makes explicit); if we can characterize the weight of our reasons to bring about states of affairs directly in terms of their value, without recourse to notions such as 'action' and 'outcome,' we remain as close as we possibly can to the basic idea. It is this observation that supports Value Determines Weight, and thus P1. And this is why it does make a difference to look at how our reasons and their weights are generated.

None of this is to say that $\mathrm{P} 1$ cannot be rejected, but I hope it at least brings out that there is a non-question-begging way of arriving at the view about how our reasons (and their weights) are generated by the value of states of affairs sketched in the foregoing, a view that arises naturally from the basic consequentialist intuition that what matters ultimately is only how good the world is, overall. I have argued that the view presented is incompatible with actualist verdicts on cases of avoidable imperfections. Those who want to defend those verdicts owe us an explanation of how to arrive at a view of the weight of practical reasons that can underwrite them in a way that comports at least as well with the basic consequentialist intuition.

Acknowledgments I am indebted to Emily Given, Nate Sharadin, several anonymous referees, and audiences at the University of Amsterdam and the University of North Carolina at Chapel Hill for comments on and discussion of earlier versions of this paper.

${ }^{19}$ For a similar sentiment regarding the usefulness of these (and some closely related) notions for consequentialist moral theorizing, see Feldman (1986: 13). 
Open Access This article is distributed under the terms of the Creative Commons Attribution License which permits any use, distribution, and reproduction in any medium, provided the original author(s) and the source are credited.

\section{References}

Bykvist K (2002) Alternative actions and the spirit of consequentialism. Philos Stud 107:45-68

Carlson E (1999) Consequentialism, alternatives, and actualism. Philos Stud 96:253-268

Castañeda HN (1968) A problem for utilitarianism. Analysis 28:141-142

Doris J (1998) Persons, situations, and virtue ethics. Noûs 32:504-530

Driver J (2008) The 'actual' in actualism. In: Ravenscroft I (ed) Minds, ethics, and conditionals. Oxford University Press, Oxford, pp 267-280

Feldman F (1986) Doing the best we can. D. Reidel Publishing Company, Dordrecht

Goble L (1993) The logic of obligation, 'better' and ‘worse'. Philos Stud 70:133-163

Goble L (1996) Utilitarian deontic logic. Philos Stud 82:317-357

Goldman HS (1976) Dated rightness and moral imperfection. Philos Rev 85:449-487

Goldman HS (1978) Doing the best one can. In: Goldman A, Kim J (eds) Values and Morals. D. Reidel Publishing Company, Dordrecht, pp 186-214

Hammond PJ (1976) Changing tastes and coherent dynamic choice. Rev Econ Stud 43:159-173

Hammond PJ (1988) Consequentialist foundations for expected utility. Theor Decis 25:25-78

Jackson F, Pargetter R (1986) Oughts, options, and actualism. Philos Rev 95:233-55

Louise J (2009) I won't do it! Self-prediction, moral obligation and moral deliberation. Philos Stud 146:327-348

McClennen E (1990) Rationality and dynamic choice. Cambridge University Press, Cambridge

Smith M (2004) Ethics and the a priori. Cambridge University Press, Cambridge

Sobel JH (1976) Utilitarianism and past and future mistakes. Noûs 10:195-219

Streumer B (2007) Reasons and impossibility. Philos Stud 136:351-384

Vessel JP (2003) Counterfactuals for consequentialists. Philos Stud 112:103-125

Vessel JP (2007) The probabilistic nature of objective consequentialism. Theoria 73:46-67

Vessel JP (2009) Defending a possibilist insight in consequentialist thought. Philos Stud 142:183-195

Vorobej M (2000) Prosaic possibilism. Philos Stud 97:131-136

Vranas P (2007) I ought, therefore I can. Philos Stud 136:167-216

Williams B (1973) A critique of utilitarianism. In: Smart JJC, Williams B (eds) Utilitarianism: for and against. Cambridge University Press, Cambridge, pp 75-150

Woodard C (2009) What's wrong with possibilism. Analysis 69:219-226

Zimmerman MJ (1996) The concept of moral obligation. Cambridge University Press, Cambridge

Zimmerman MJ (2006) The relevance of risk to wrongdoing. In: Feldman R, McDaniel K, Raibly J, Zimmerman MJ (eds) The good, the right, life, and death. Ashgate, Aldershot, pp 151-170 